\title{
Attitudes toward opioid use for chronic pain: A Canadian physician survey
}

\author{
Patricia K Morley-Forster $\mathrm{MD}^{1}$, Alexander J Clark $\mathrm{MD}^{2}$, Mark Speechley $\mathrm{PhD}^{1}$, Dwight E Moulin $\mathrm{MD}^{1}$
}

PK Morley-Forster, AJ Clark, M Speechley, DE Moulin. Attitudes toward opioid use for chronic pain: A Canadian physician survey. Pain Res Manage 2003;8(4):189-194.

OBJECTIVES: To measure chronic pain patient volumes seen in primary care practice; to determine what medications physicians choose for the treatment of moderate to severe chronic pain; to identify barriers to the use of opioids in the treatment of chronic pain; and to assess physicians' attitudes toward the current management of chronic pain in Canada.

DESIGN: A computer-assisted telephone survey of 100 regionally representative Canadian physicians with a defined interest in palliative care (PC, $n=30)$ or noncancer pain (GP, $n=70)$.

SETTING: A survey was conducted by Ipsos-Reid in June 2001. Only physicians who met the eligibility criteria of having written 20 or more prescriptions for moderate to severe pain in the preceding four weeks or having devoted $20 \%$ of time to palliative care were eligible to participate.

RESULTS: In one month, the average number of patients with moderate to severe chronic pain seen by PCs was 94.2 ; the average seen by GPs was 44.7 . The pain experienced by $83.3 \%$ of GP patients was noncancer related. For chronic cancer pain, an opioid analgesic was the treatment of choice of $79 \%$ of physicians (48\% preferred morphine, $21 \%$ codeine, $10 \%$ other). For moderate to severe chronic noncancer pain, opioids were the first-line treatment of only $32 \%$ of physicians (16\% preferred codeine, $16 \%$ major opioids) because a significant number preferred either nonsteriodal anti-inflammatory drugs $(29 \%)$ or acetaminophen (16\%). Thirty-five per cent of GPs and $23 \%$ of PCs would never use opioids for noncancer pain, even when described as severe.

Chronic pain was deemed by $68 \%$ of physicians to be inadequately managed. Almost $60 \%$ thought that pain management could be enhanced by improved physician education. Identified barriers to opioid use included addiction potential (37\%) and side effects (25\%). Seventeen per cent of GPs and $10 \%$ of PCs thought that regulatory sanctions limited opioid prescribing.

CONCLUSIONS: Even among physicians experienced in chronic pain treatment, there is a reluctance to use opioids for severe nonmalignant pain. One-half of the survey participants believed that there was a need for improved physician education in pain management, including the use of opioids.

Key Words: Analgesics; Chronic pain; Opioids; Physicians; Treatment

\section{Attitudes à l'égard de l'utilisation des opioïdes pour le soulagement de la douleur chronique : enquête menée auprès de médecins au Canada}

OBJECTIFS : Mesurer la patientèle vue en soins primaires pour des douleurs chroniques; déterminer les préférences des médecins quant aux médicaments prescrits pour le soulagement de la douleur chronique modérée ou intense; cerner les obstacles à l'utilisation des opioïdes pour le traitement de la douleur chronique; évaluer l'attitude des médecins à l'égard du traitement actuel de la douleur chronique au Canada.

MODÈLE D'ÉTUDE : Enquête téléphonique assistée par ordinateur auprès de 100 médecins représentatifs des régions, ayant un intérêt particulier pour les soins palliatifs (SP; $n=30$ ) ou la douleur d'origine non cancéreuse ( $M G$ [médecine générale]; n=70).

MILIEU : L'enquête a été réalisée par Ipsos-Reid en juin 2001. Seuls les médecins qui répondaient aux critères de sélection, c'est-à-dire qui avaient rédigé au moins 20 prescriptions pour le soulagement de douleurs modérées ou intenses au cours des quatre semaines précédentes ou qui avaient consacré plus de $20 \%$ de leur temps aux soins palliatifs, pouvaient participer à l'étude.

RÉSULTATS : Le nombre mensuel moyen de patients vus en SP pour des douleurs chroniques modérées ou intenses était de 94,2; celui en MG, de 44,7. Dans $83,3 \%$ des cas en MG, la douleur n'était pas d'origine cancéreuse. Pour les douleurs chroniques néoplasiques, $79 \%$ des médecins ont préféré un opioïde comme analgésique de premier recours (48\% : morphine; $21 \%$ : codéine; $10 \%$ : autres). Pour ce qui est des douleurs chroniques modérées ou intenses, d'origine non cancéreuse, $32 \%$ seulement des médecins ont prescrit des opioïdes comme médicaments de première intention ( $16 \%$ : codéine; $16 \%$ : opioïdes forts); les autres ont choisi en majorité des anti-inflammatoires non stéroïdiens (29\%) ou l'acétaminophène (16\%). Par ailleurs, certains médecins (35\% en MG; $23 \%$ en SP) n'ont jamais prescrit d'opioïdes pour le traitement de douleurs non néoplasiques, même fortes. D'après $68 \%$ des médecins, le traitement de la douleur chronique laisse à désirer. Presque $60 \%$ des répondants étaient d'avis qu'une meilleure formation en la matière pourrait améliorer le traitement de la douleur. Les risques de dépendance (37\%) et les effets indésirables ( $25 \%)$ ont été cités comme les principaux obstacles à l'utilisation des opioïdes. Enfin, $17 \%$ des médecins généralistes et $10 \%$ des médecins en SP considéraient que les sanctions réglementaires limitaient le recours aux opioïdes.

CONCLUSION : Même chez les médecins rompus au traitement de la douleur chronique, on décèle une certaine réticence à utiliser les opioïdes pour le soulagement de douleurs intenses, non néoplasiques. D'après la moitié des répondants, les médecins auraient besoin d'une meilleure formation en ce qui concerne le traitement de la douleur, y compris le recours aux opioïdes.

${ }^{1}$ University of Western Ontario Interdisciplinary Pain Program, London, Ontario; ${ }^{2}$ Pain Management Unit, Capital Health and Dalhousie University, Halifax, Nova Scotia

Correspondence: Dr Pat Morley-Forster, St Joseph's Health Care, Room F208, 268 Grosvenor Street, London, Ontario N6A 4L6.

Telephone 519-646-6000 ext 65065, fax 519-646-6376, e-mail pat.morley-forster@sjhc.london.on.ca 
A recently published Canadian survey identified the prevalence of chronic pain, defined as pain persisting more than six months, to be approximately $29 \%$ in individuals 18 years of age and older (1). Moulin et al (1) concluded that the known therapeutic benefits of opioids are underutilized in Canada for moderate to severe chronic pain. This conclusion was supported by the findings from another recent survey reviewing patients presenting to a tertiary pain clinic in Ontario for enrollment in clinical trials (2). Forty-one per cent of patients with documented neuropathic pain had never been prescribed an opioid despite the presence of inadequate pain control in almost $75 \%$ of that population.

What are the obstacles to Canadian physicians' use of opioids for nonmalignant pain? A survey of primary care physicians in California found that $35 \%$ were not willing to prescribe sustained-release opioids around the clock for chronic pain patients under any circumstances (3). The most significant predictor of willingness to prescribe opioids was a lower level of concern about physical dependence, tolerance and addiction. No data have yet been published on Canadian primary care physicians' attitudes toward prescribing opioids for chronic noncancer pain.

The objectives of the present survey were to measure the volumes of chronic pain patients seen by family practitioners (GPs) and palliative care physicians (PCs) in Canada, to determine what medications they would use to treat moderate to severe chronic pain, to identify barriers to the use of strong opioids in the treatment of chronic pain, and to assess attitudes toward the current management of chronic pain in Canada.

\section{METHODS}

The survey was carried out by Ipsos-Reid HealthCare Canada, a firm that specializes in Canadian market research related to physicians and health care consumers. The survey was conducted at the same time as a companion survey designed to assess the prevalence of chronic pain among Canadian adults (1). In June 2001, 100 physicians, drawn from a nationally representative sample of physicians, were interviewed by a computer-assisted telephone interview using random digital dialing. To ensure that randomized stratification was achieved, quotas were set for each region based on physician distribution; physicians within each region were then randomly selected until the target number was reached. The interview lasted approximately $30 \mathrm{~min}$ and was conducted in English or French according to the physician's preference. The interviewers were full-time professionals who were trained in survey techniques and randomly audited. A pilot survey of eight interviews was administered to test the questionnaire.

The physician's name and contact information were taken from the Canadian Medical Directory as published by Southam Information Group (Canada). This database, updated annually, contains 50,590 licensed physicians of whom approximately $55 \%$ are stated to be in primary care. A computerized random number generator selected out the physicians to be called within each region. Physicians were contacted a maximum of four times before being considered nonresponders. Contact was judged to be established by any of the following: speaking directly with the doctor; leaving a message with a receptionist or answering machine; or by sending a fax, letter or e-mail. An honorarium was offered. If they declined to participate, they were asked to state a reason for their
TABLE 1

Volume of pain patients per four-week period

\begin{tabular}{lcc}
\hline & $\begin{array}{c}\text { PCs } \\
(\mathbf{n = 3 0 )}\end{array}$ & $\begin{array}{c}\text { GPs } \\
(\mathbf{n = 7 0 )}\end{array}$ \\
\hline Median & 65 & 25 \\
Average & 94.2 & 44.7 \\
Cancer pain (\%) & $66.8 \%$ & $16.7 \%$ \\
\hline
\end{tabular}

The question posed to physicians with a defined interest in palliative care (PCs) or noncancer pain (GPS) was, "In a typical four-week period, how many patients do you see for moderate to severe chronic pain, both cancer and noncancer?" The majority of patients seen by GPs were for noncancer pain (83.3\%)

declination. Typical reasons for refusal were not available, too busy at the moment, insufficient incentive and "never do surveys".

To ensure that the physicians surveyed had a significant interest in cancer pain and/or chronic pain, they had to meet certain eligibility criteria. To be defined as having an interest in chronic pain (ie, GPs), the doctor had to report having written 20 or more prescriptions for any type of moderate to severe chronic pain in the preceding four weeks. To be included in the palliative care group (ie, PCs), the physician had to have written more than 40 prescriptions for palliative care and have devoted more than $20 \%$ of their time to it in the preceding four weeks.

To determine treatment algorithms for chronic noncancer pain, the following questions were posed: "When you initiate drug therapy in moderate to severe chronic noncancer pain, which drug is your current first-line preference?"; "If the first drug you prescribe proves unsatisfactory for whatever reason, what would you be most likely to prescribe next?"; and "If the second drug you prescribed proved unsatisfactory what then would you be most likely to prescribe?"

To identify barriers to strong opioid use, physicians were asked: "What obstacles or barriers, if any, hinder your use of strong opioid analgesics in chronic noncancer pain?" The first or 'top-of-mind' mention was recorded and tabulated separately. All other mentions were recorded and analyzed as "all mentions combined". Codeine was classified as a weak opioid; all others were defined as strong opioids.

To conclude the survey, respondents were asked questions about their opinions on the quality of chronic pain management in Canada, the consequences of poor pain treatment and their suggestions for improvement. A series of statements were read to them and they rated their agreement or disagreement with each statement on a 7-point scale, with 7 indicating strong agreement.

Interview data were analyzed using SPSS (Version 10.2, SPSS Inc, USA). Means and 95\% CIs were calculated using SPSS, which allowed for sample weighting.

\section{Chronic pain volumes}

\section{RESULTS}

Seventy GPs and 30 PCs were identified and completed the survey. When unanswered calls and physicians who did not meet the eligibility criteria regarding practice time devoted to pain management and number of prescriptions recently written were excluded, the response rate was approximately $70 \%$.

The PCs devoted $47 \%$ of their time to palliative care and saw an average of 94.2 patients with moderate to severe pain in the preceding four weeks (Table 1). The average number of patients in significant pain seen by the GPs in the same time 
TABLE 2

Third-line treatment choice for chronic noncancer pain

\begin{tabular}{lcc}
\hline & $\begin{array}{c}\text { PCs } \\
(\mathbf{n = 3 0 )}\end{array}$ & $\begin{array}{c}\text { GPs } \\
(\mathbf{n = 7 0 )}\end{array}$ \\
\hline Percentage of physicians who & 77 & 65 \\
$\quad$ would prescribe an opioid (\%) & 7 & \\
Codeine (\%) & 27 & 21 \\
Morphine (short or long acting) (\%) & 33 & 13 \\
Oxycodone (short or long acting) (\%) & 10 & 7 \\
Other opioids (hydromorphone, & & \\
$\quad$ transdermal fentatnyl) (\%) & 0 & 7 \\
Nonsteroidal anti-inflammatory drug only (\%) & 0 &
\end{tabular}

The question posed was, "If Drug $A$ and Drug $B$ both prove unsatisfactory, what would be your third-line choice?" GP Physician with a strong interest in noncancer pain; $P C$ Physician with a strong interest in palliative care

period was 44.7. In the four weeks preceding the survey, the PCs estimated that they had written 134 prescriptions for moderate to severe pain versus 55 by GPs. Cancer patients were in the minority. Among the GPs, $83.3 \%$ of pain patients experienced noncancer-related pain, whereas $33.2 \%$ of pain patients seen by the PCs had nonmalignant pain.

\section{Treatment algorithms}

For moderate to severe chronic noncancer pain, an opioid was first-line treatment for only $37 \%$ of the PCs and $30 \%$ of the GPs. Large minorities preferred nonsteroidal anti-inflammatory drugs $(29 \%)$ or acetaminophen (16\%). Almost two-thirds of physicians (63\%) would revert to opioids as second-line treatment. However, $23 \%$ of PCs and $35 \%$ of GPs would not use opioids to treat moderate to severe chronic noncancer pain even as a third-line treatment after two previous medications had failed (Table 2).

\section{Barriers to strong opioid use}

When all mentions were combined, the five most commonly cited obstacles to strong opioid use were as follows (Figure 1):

1. Potential for addiction (PCs 30\%, GPs 40\%)

2. Potential for patient abuse/misuse (PCs 23\%, GPs 31\%)

3. Unspecified side effects (PCs 17\%, GPs 29\%), especially drowsiness and cognitive impairment in elderly patients

\section{Constipation (PCs 7\%, GPs 20\%)}

\section{Fear of a College audit (PCs 10\%, GPs 17\%)}

There is an apparent discrepancy in the responses in that the GPs seemed to fear the process of a College audit more that the PCs, who were less concerned about this possibility. However, the PCs had concerns regarding the legal liability of prescribing opioids, with the potential for loss of licensure, which apparently were not shared by the GPs. Unfortunately, the survey format did not allow for further exploration of these concerns.

Other concerns mentioned by more than $5 \%$ of physicians were that the long-acting opioids were expensive and not always covered by provincial health insurance plans, and that tolerance may develop.

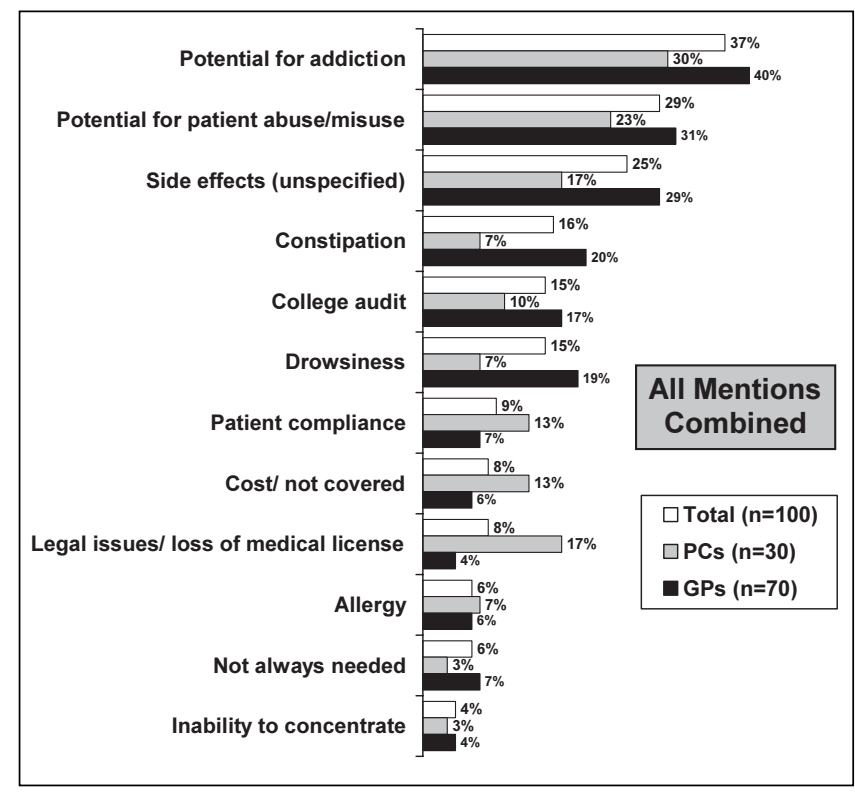

Figure 1) Barriers to greater use of strong opioids (unaided). Physicians with a defined interest in palliative care (PCs) or noncancer pain (GPs) were asked the following question: "What obstacles or barriers, if any, are there that hinder your use of strong opioid analgesics in chronic noncancer pain?" They were asked initially to spontaneously state the first factor that came to mind, which was recorded separately (top-of-mind mentions). All other mentions were then recorded (all mentions combined)

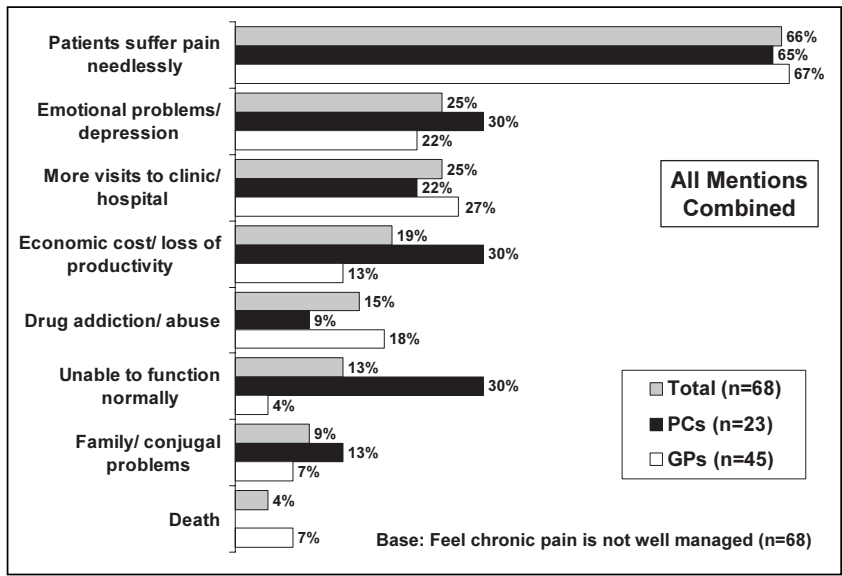

Figure 2) Consequences of poor chronic pain management. Physicians who agreed with the statement "chronic pain is not well managed in Canada" ( $n=68$ ) were asked the following question: "What are the consequences of poor pain management, in your opinion?" They were asked initially to spontaneously state the first factor that came to mind, which was recorded separately (top-of-mind mentions). All other mentions were then recorded (all mentions combined). GP Physician with a defined interest in noncancer pain; PC Physician with a defined interest in palliative care

Attitudes toward chronic pain management

When PCs and GPs were combined, a total of $68 \%$ thought that moderate to severe chronic pain was not well managed in Canada. The perceived consequences of this were that patients suffered pain needlessly, leading to emotional problems and depression in both patients and their families. Other consequences listed were increased use of the health care system, loss of work productivity and drug addiction (Figure 2). 


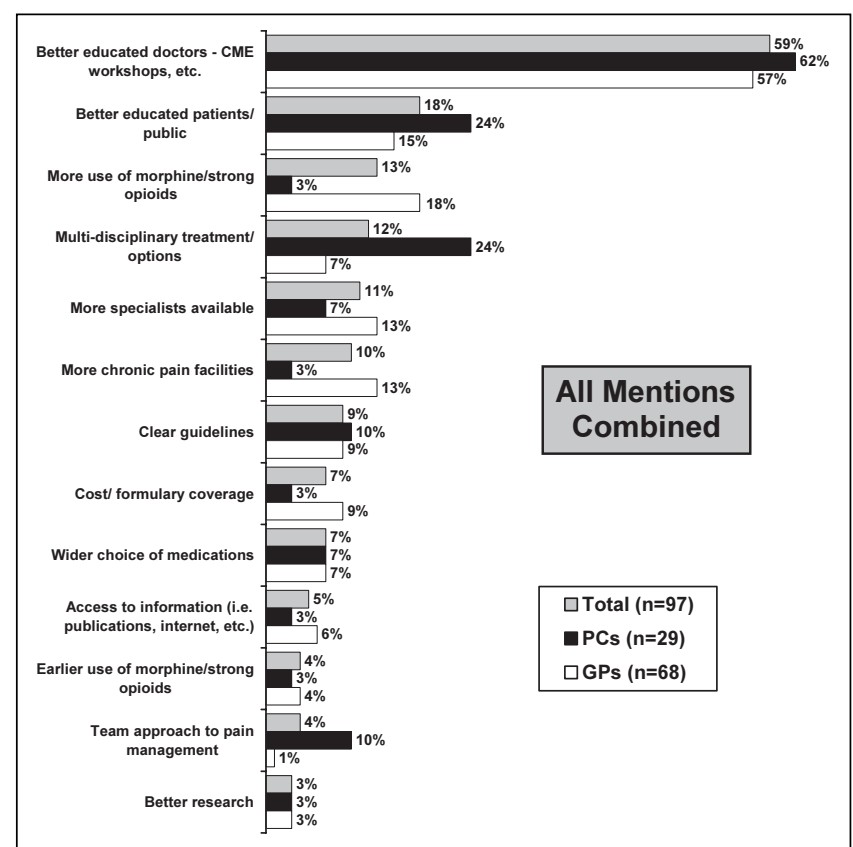

Figure 3) Suggested improvements in chronic pain management. Physicians who agreed with the statement that "chronic pain is somewhat well managed in Canada" $(n=97)$ were asked the following question: "How, in your opinion, can the management of chronic pain in Canada be improved?" They were asked initially to spontaneously state the first factor that came to mind, which was recorded separately (topof-mind mentions). All other mentions were then recorded (all mentions combined). CME Continuing medical education; GP Physician with a defined interest in noncancer pain; PC Physician with a defined interest in palliative care

Almost $60 \%$ of all physicians surveyed thought that improving education of physicians could enhance pain management. Other commonly mentioned strategies for improvement were educating the public, creating more multidisciplinary pain treatment facilities and increasing prescribing of strong opioids (Figure 3).

Two-thirds of the respondents agreed with the statement that strong opioids are very useful in managing chronic pain. A similar number were aware that the current trend is toward the use of long-acting opioids, and they agreed that the benefits of opioids outweighed the disadvantages (Figure 4).

\section{DISCUSSION}

Approximately 28\% of Canadian physicians surveyed, chosen for their interest in pain management, were unwilling to prescribe either short- or long-acting opioids for chronic noncancer pain even when two other medications had proven ineffective. This figure seems high in light of growing acceptance of the benefits of long-acting opioid therapy in this group of patients $(1,4)$. It is especially surprising when one considers that the physicians surveyed were self-described as writing a high volume of prescriptions for moderate to severe pain. However, the figure is comparable to recent data from a California survey on the attitudes of primary care physicians to opioid prescribing for chronic pain (3). Potter et al (3) reported that $35 \%$ of family physicians who were surveyed in the Stanford Collaborative Research Network refused to prescribe

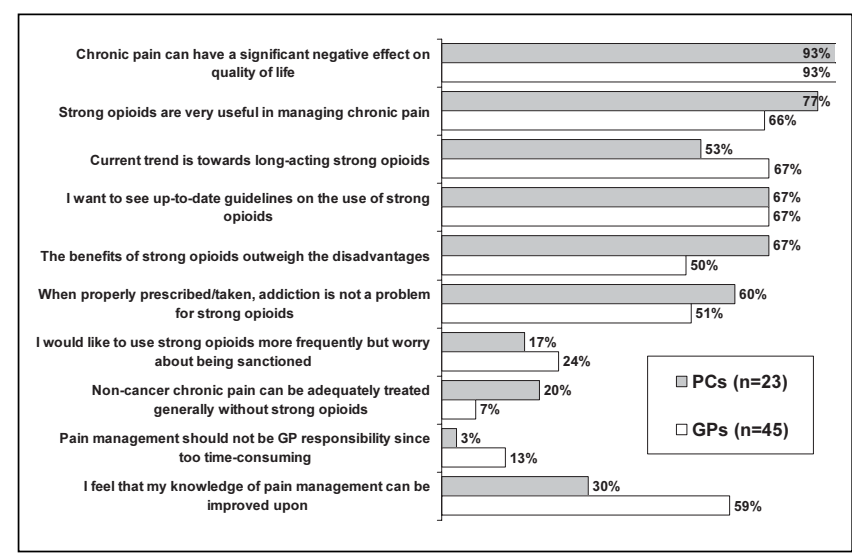

Figure 4) Attitudes toward management of chronic pain. A series of statements regarding the use of opioids in pain management was read to the physicians and they were asked to rate their agreement on a 7-point scale, with 7 indicating complete agreement. The numbers of doctors rating their agreement as either 6 or 7 were combined for ease of analysis. They were asked initially to spontaneously state the first factor that came to mind, which was recorded separately (top-of-mind mentions). All other mentions were then recorded (all mentions combined). GP Physician with a defined interest in noncancer pain; PC Physician with a defined interest in palliative care

sustained-release morphine for noncancer pain that persisted unchanged after exhaustive evaluation and treatment attempts.

Concerns about addiction and/or dependence were the most frequently cited reasons in both American and Canadian groups, although the percentages are not directly comparable because of differences in survey methodology. The California survey offered three clinical vignettes: chronic back pain, postherpetic neuralgia and chronic daily headache. Concern about the potential for opioids to cause addiction in headache patients was very high at $74 \%$, whereas concern for patients with chronic low back pain was cited by $29 \%$ of physicians. This latter figure is comparable to the Canadian figure of $30 \%$ who rated addiction as a major concern.

In the California survey, $40 \%$ of physicians stated that fear of legal investigation tempered their use of opioids for chronic noncancer pain. The number in Canada was much lower at $10 \%$ of PCs and $17 \%$ of GPs. The official stance of regulatory bodies in Canada is that they support the treatment of noncancer pain with strong opioids with appropriate prescribing and monitoring. The College of Physicians and Surgeons of Ontario has published evidence-based recommendations for the medical management of chronic pain (5). These Guidelines follow general principles of sound medical practice including documentation of diagnosis, screening for addiction, preferred use of long-acting opioids over short-acting ones, use of an opioid contract and monitoring of side effects. Two-thirds of surveyed physicians requested that up-to-date guidelines be set in place, suggesting that the College Guidelines are not widely known (Figure 4).

The message that long-acting opioids are safe and effective with appropriate screening and monitoring is slowly gaining acceptance. There are now 10 high-quality randomized controlled trials, published in the last seven years, which demonstrate that the use of long-acting opioids for chronic noncancer 
pain can reduce pain intensity and improve functioning (6-15). Increased prescribing of opioids between 1990 and 1996 in North America did not result in increased abuse, supporting the idea that it is not exposure to opioids alone that causes addiction but rather a complex interplay of biopsychosocial factors (16).

The majority of physicians surveyed $(68 \%)$ thought that chronic pain was not well managed in Canada. Almost one-half of the physicians surveyed thought that improvements needed to be made in physician education in the form of case studies, workshops, etc. Patient education was also suggested. The fact that patients often carry exaggerated misconceptions about opioid use was confirmed by Gilron and Bailey's (2) survey of neuropathic pain patients, in whom fear of addiction was expressed by $32 \%$.

In Potter et al's study (3), recent graduation from medical school was a predictor of increased willingness to prescribe opioids. This may reflect either more knowledge on the part of new graduates or less experience with the negative consequences of opioids. Until very recently, pain management was given negligible attention in medical training curricula. This situation is improving in most Canadian medical schools with increasing number of lecture hours and case-oriented seminars dedicated to cancer pain and chronic noncancer pain. However, attitudes are as important in the education process as facts. By following medical students from their freshman year to their senior years, Weinstein et al (17) discovered that the professionalization process inherent to medical schools reinforced negative attitudes about chronic pain, especially toward addiction.

Turk et al (18) published a survey in 1994 comparing the attitudes toward opioid prescription for chronic noncancer pain of medical and surgical specialties to primary care. Almost 7000 physicians, regionally represented, were requested to participate, with a response rate of $27.5 \%$ (18). Rheumatologists and general practitioners were much more willing to prescribe opioids on a long-term basis than surgeons, neurologists and physiatrists. All respondents indicated that their medical education regarding pain treatment had been inadequate.

Almost $40 \%$ of respondents in this survey stated that pain specialists or treatment facilities were not common where they practised, resulting in lengthy waiting lists. This was comparable to the California survey, in which $45 \%$ of respondents thought they had inadequate consultation and referral resources to assist with chronic noncancer pain management. Given that the prevalence of chronic pain in Canada may be as high as $29 \%$ (about 8.7 million people), it is evident that only a small percentage of pain sufferers can be managed within a specialized pain treatment facility. The main burden of care will therefore fall to family practitioners. The growing shortage of family physicians in Canada combined with our aging population suggests that the need will be difficult to meet. A small number of physicians surveyed thought that pain management should not be a family practice responsibility because it was too time-consuming (Figure 4). However, this attitude was not representative and may refer to complex pain problems, which indeed may be more appropriately managed in a multidisciplinary pain program.

Other potential reasons for physicians' reluctance to prescribe opioids exist in addition to those previously cited.
Family doctors may be uncomfortable with the wide interpatient variability demonstrated in response to opioid therapy. Patients on long-term opioids may go into withdrawal if they run out of their medication, necessitating after-hours coverage, which is difficult for solo practitioners. Depending on their area of practice, fear of diversion may be an all-too-realistic concern.

Although further research into effective pain treatment modalities was deemed important by only a small fraction of physicians, it may well be that research holds the key to improved pain management. Research into effective education strategies would certainly be a high priority. Computerized registries of patients maintained on opioids long-term are needed to prove the safety and continued efficacy of this treatment. More efficacious nonopioid drugs are needed to treat severe neuropathic and inflammatory pain. As well, novel agents that target peripheral opioid receptors would reduce the risk of both addiction and cognitive impairment.

\section{STUDY LIMITATIONS}

One limitation of the present survey was that physician characteristics such as age, sex, ethnicity and rural versus urban practice were not identified. Although the sample was regionally representative, it was a small sample relative to the large population of Canadian physicians. The estimates of volume of patients seen, prescriptions written for pain and proportions of patients with noncancer pain were reported retrospectively and were therefore subject to inaccurate recollection.

The inclusion criteria might have skewed the results. Physicians were not eligible if they did not write at least 20 prescriptions for moderate to severe pain in the preceding four weeks or devote a significant amount of time to palliative care. Whether this made them more comfortable with the use of opioids or more likely to be influenced by negative clinical experiences with opioids is difficult to judge.

\section{CONCLUSION}

These results support the need for greater physician knowledge of rational use of opioids, increased acceptance of the practice by regulators, and wider public and political awareness of the need for effective pain management in Canada.

ACKNOWLEDGEMENTS: This study was supported by an unrestricted grant from Janssen-Ortho Inc, Toronto, Ontario.

\section{REFERENCES}

1. Moulin DE, Clark AJ, Speechley M, Morley-Forster PK. Chronic pain in Canada - Prevalence, treatment, impact and the role of opioid analgesia. Pain Res Manage 2002;7:179-84.

2. Gilron I, Bailey JM. Trends in opioid use for chronic neuropathic pain: A survey of patients pursuing enrollment in clinical trials. Can J Anesth 2003;50:42-7.

3. Potter M, Schafer S, Gonzalez-Mendez E, et al. Opioids for chronic non-malignant pain. Attitudes and practices of primary care physicians in the UCSF/Stanford Collaborative Research Network. University of California, San Francisco. J Fam Pract 2001;50:145-51.

4. Clark AJ, Lynch ME. Opioid therapy and chronic non-cancer pain. Can J Anesth 2003;50:1-4.

5. Jovey RD, Ennis J, Gardner-Nix J, et al. Use of opioid analgesics for the treatment of chronic non-cancer pain. J Pain 2002;2:197-204.

6. Moulin DE, Iezzi A, Amireh R, Sharpe WK, Boyd D, Merskey H. Randomized trial of oral morphine for chronic non-cancer pain. Lancet 1996;347:143-7. 
7. Watson CP, Moulin DE, Watt-Watson J, Gordon A, Eisenhoffer J. Controlled-release oxycodone relieves neuropathic pain: A randomized controlled trial in painful diabetic neuropathy. Pain 2003;105:71-8.

8. Watson CP, Babul N. Efficacy of oxycodone in neuropathic pain: A randomized trial in postherpetic neuralgia. Neurology 1998;50:1837-41.

9. Roth SH, Fleischmann RM, Burch FX, et al. Around-the-clock, controlled-release oxycodone therapy for osteoarthritis-related pain Placebo-controlled trial and long-term evaluation. Arch Intern Med 2000;160:853-60.

10. Caldwell JR, Hale ME, Boyd RE, et al. Treatment of osteoarthritis pain with controlled release oxycodone or fixed combination oxycodone plus acetaminophen added to nonsteroidal antiinflammatory drugs: A double blind, randomized, multicentre, placebo controlled trial. J Rheumatol 1999;26:862-9.

11. Arkinstall W, Sandler A, Goughnour B, Babul N, Harsanyi Z, Darke AC. Efficacy of controlled-release codeine in chronic non-malignant pain: A randomized, placebo-controlled trial. Pain 1995;62:169-78.
12. Peloso PM, Bellamy N, Bensen W, et al. Double blind randomized placebo controlled trial of controlled release codeine in the treatment of osteoarthritis of the hip or knee. J Rheumatol 2000;27:764-71.

13. Raja SN, Haythornthwaite JA, Pappagallo M, et al. Opioids versus antidepressants in postherpetic neuralgia: A randomized, placebocontrolled trial. Neurology 2002;59:1015-21.

14. Huse E, Larbig W, Flor H, Birbaumer N. The effect of opioids on phantom limb pain and cortical reorganization. Pain 2001;90:47-55.

15. Gimbel JS, Richards P, Portenoy RK. Controlled release oxycodone for pain in diabetic neuropathy. Neurology 2003;60:927-34.

16. Joranson DE, Ryan KM, Gilson AM, Dahl JL. Trends in medical use and abuse of opioid analgesics. JAMA 2000;283:1710-4.

17. Weinstein SM, Laux LF, Thornby JI, et al. Medical students' attitudes toward pain and the use of opioid analgesics: Implications for changing medical school curriculum. South Med J 2000;93:472-8.

18. Turk DC, Brody MC, Okifuji EA. Physicians' attitudes and practices regarding the long-term prescribing of opioids for non-cancer pain. Pain 1994;59:201-8. 


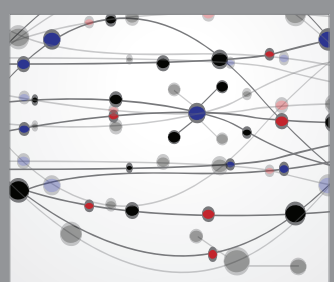

The Scientific World Journal
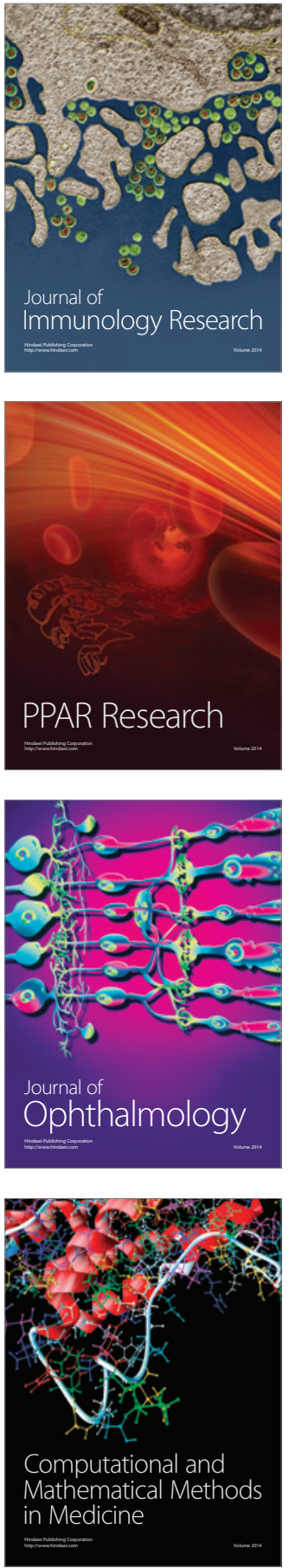

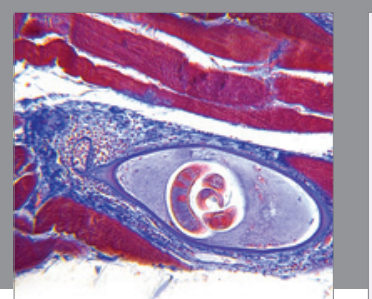

Gastroenterology Research and Practice

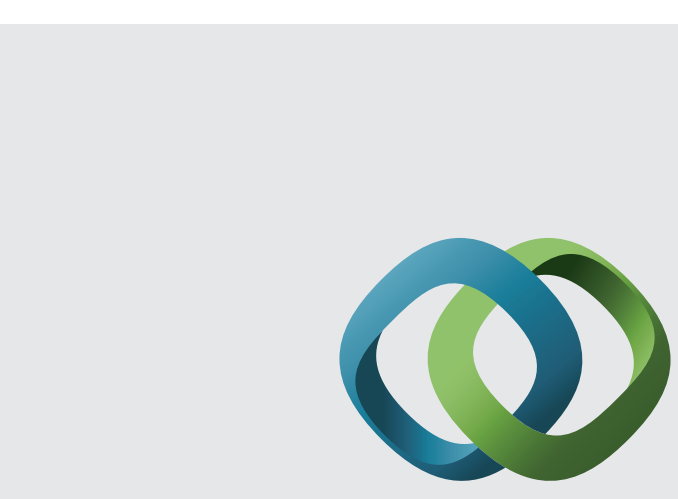

\section{Hindawi}

Submit your manuscripts at

http://www.hindawi.com
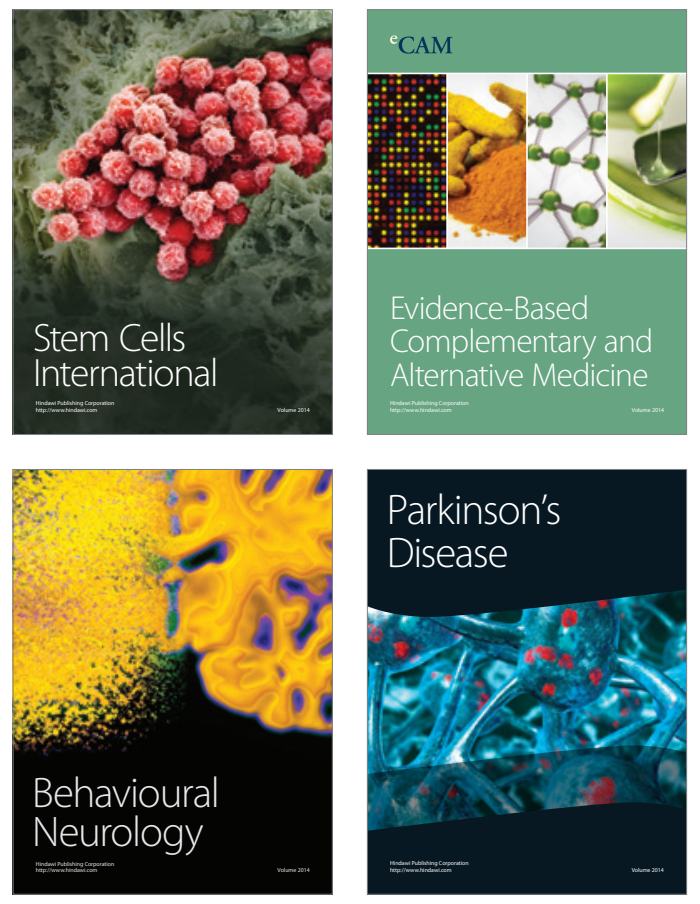
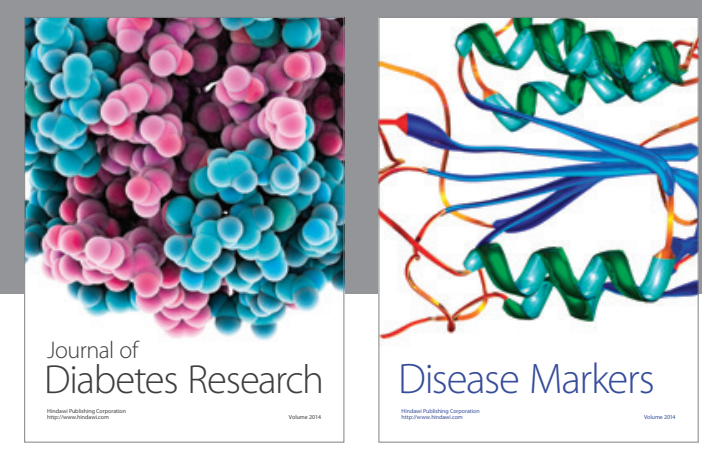

Disease Markers
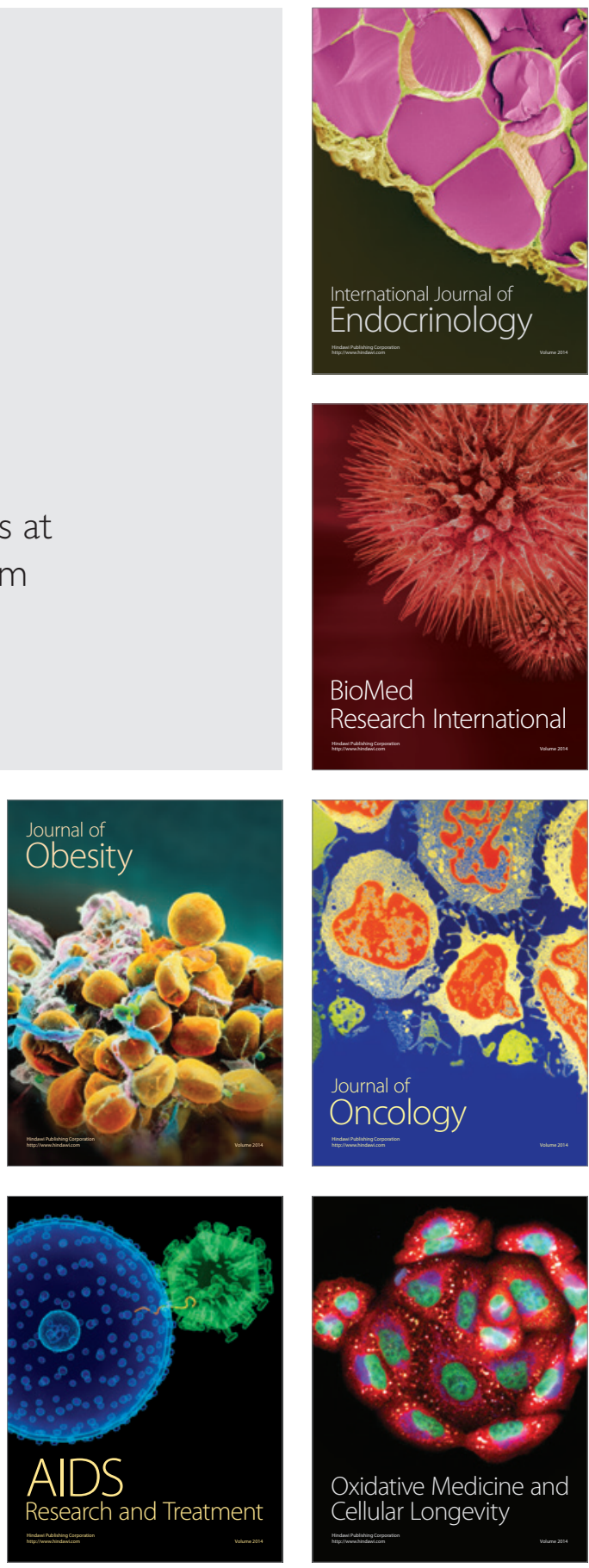